\title{
Solar Electric Propulsion for Future NASA Missions
}

\author{
Geoffrey A. Landis, Steven R. Oleson, and Carolyn R. Mercer \\ NASA Glenn Research Center, 21000 Brookpark Road, Cleveland OH 44135
}

\begin{abstract}
Use of high-power solar arrays, at power levels ranging from $\sim 500 \mathrm{KW}$ to several megawatts, has been proposed for a solar-electric propulsion (SEP) demonstration mission, using a photovoltaic array to provide energy to a high-power xenon-fueled engine. One of the proposed applications of the high-power SEP technology is a mission to rendezvous with an asteroid and move it into lunar orbit for human exploration, the Asteroid Retrieval mission. The Solar Electric Propulsion project is dedicated to developing critical technologies to enable trips to further away destinations such as Mars or asteroids. NASA needs to reduce the cost of these ambitious exploration missions. High power and high efficiency SEP systems will require much less propellant to meet those requirements.
\end{abstract}

\section{INTRODUCTION}

Use of high-power solar arrays, at power levels ranging from $\sim 500 \mathrm{KW}$ to several megawatts, has been proposed as the power source for solar-electric propulsion (SEP) missions [1-4]. In this propulsion system, high-power photovoltaic arrays provide energy's to a xenon-fueled electrical engine. One of the proposed applications of the high-power SEP technology is a mission to rendezvous with an asteroid and move it into lunar orbit, or else to select a boulder on the surface to move into lunar orbit, for human exploration: the Asteroid Redirect mission [4].

The Solar Electric Propulsion (SEP) project is dedicated to developing critical technologies to enable trips to further away destinations such as Mars [5] or asteroids. In order to make this technology practical, NASA needs to reduce the cost of these ambitious exploration missions. High power and high efficiency SEP systems will require much less propellant to meet those requirements. The new system will use Xenon propellant energized by electric power from solar arrays. The higher exhaust velocity achieved allows a factor of ten reduction in propellant usage compared to typical chemical propulsion system like the engines on the space shuttle.

Large solar arrays and high power thrusters are being developed for flight into space. Compared with current systems, they will have a target improvement of a factor of two in specific power, use a factor of four less storage for electricity produced, and will be able to withstand four times the ionizing radiation dose. For launch, SEP solar arrays must stow into very small, lightweight packages and then unfurl to cover a very large area to capture enough solar energy to produce high levels of electrical power. They also need to be durable so that they can operate for a long time in places like low Earth orbit and the Van Allen radiation belt.

SEP uses electrical propulsion, such as electrostatic ion thrusters $[6,7]$ or stationary plasma thrusters ("Hall thrusters") instead of a chemical rocket engine. Both of these thrusters emit electrons from an external cathode for neutralization.

Several technology demonstration mission concepts for Solar Electric Propulsion have been analyzed. These include both missions in Earth orbit, in which solar arrays provide power for an electric propulsion system to do orbit-raising through the Van Allen radiation belts, and missions further into the solar system, analyzing operation of high-power solar propulsion systems in interplanetary space.

\section{THE NASA ASTEROID MISSION, ARRM}

This mission is a concept under study by NASA that would use solar electric propulsion to bring a small Near Earth Asteroid (NEA), or a portion of such an asteroid, into a distant orbit around the moon, where it could be examined and explored by astronauts.

The current plan for the asteroid mission, the Asteroid Robotic Redirect Mission (ARRM), will capture a large (up to 1000 metric ton) boulder from the surface of a Near Earth Asteroid, and bring it into high lunar orbit.

Figure 2 shows the conceptual design of the solar electric propulsion bus, showing how the mission could be configured using either of two different solar array designs currently being developed [4]. The reference mission shown would use a 58-kW solar array, powering a $40-\mathrm{kW}$ Electric Propulsion (EP) system.

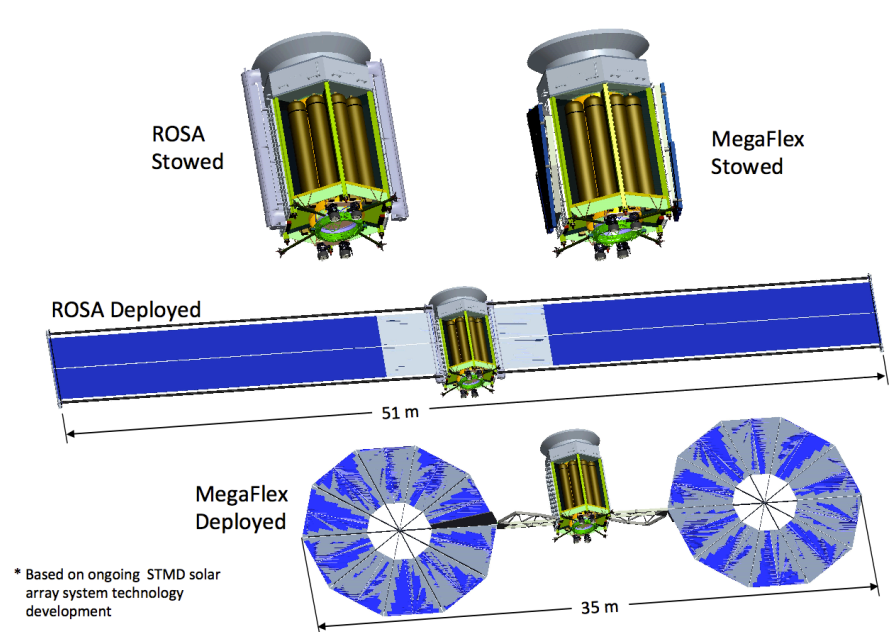

Fig. 1 Conceptual diagram of a reference version of the proposed Asteroid Robotic Redirect Mission spacecraft, showing two choices of solar arrays, both retracted (top) and deployed (bottom) (from [4]). 
The capture, transportation, examination and dissection of a portion of a NEA would provide valuable information for planetary defense and a unique, meaningful and affordable destination for future robotic and human exploration.

The feasibility of the asteroid mission is enabled by three key developments: the ability to discover and characterize an adequate number of sufficiently small near-Earth asteroids for capture and return; the ability to implement sufficiently powerful solar electric propulsion systems to enable transportation of the captured NEA; and the proposed human presence in cislunar space in the 2020s enabling exploration and exploitation of the returned NEA.

The proposed purpose of the asteroid mission is not merely to conduct asteroid science, however, but also to be a technology groundbreaking mission to demonstrate in a functioning mission the $100-\mathrm{kW}$ class solar electric propulsion technologies that will then be instrumental in human missions to Mars.

\section{HUMAN MARS MISSION}

Farther into the future, solar electric propulsion is one of the leading candidates for transportation for future human missions to Mars [5]. This will require arrays with power of 1 MW and higher. Figure 2 shows a conceptual design of a proposed SEP transfer vehicle for a future Mars mission.

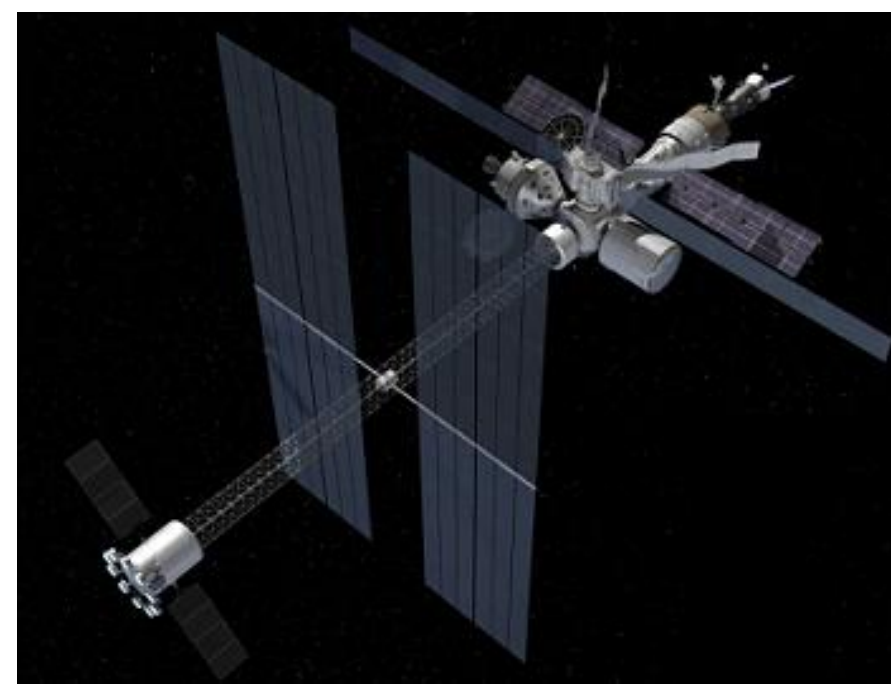

Fig. 2. Conceptual design of a proposed Mars transfer vehicle.

\section{TECHNOLOGY DEMONSTRATION Missions}

Several candidate missions have been analyzed to serve as technology demonstration of the key elements of high power array technology needed for the exploration missions. Figure 3 shows one such mission to large, light flexible solar arrays $(>15 \mathrm{~kW}$ each), demonstrate high power Hall thrusters (12 $\mathrm{kW})$ and throughput $>750 \mathrm{~kg}$ Xenon, and demonstrate orbit raising and maneuvers through the Earth's Van Allen belts with a large SEP system. This technology demonstration is designed to be launched as a "ride share" with a payload to Geosynchronous Transfer Orbit (GTO), to keep the mission within a $\$ 300 \mathrm{M}$ dollar cost cap.

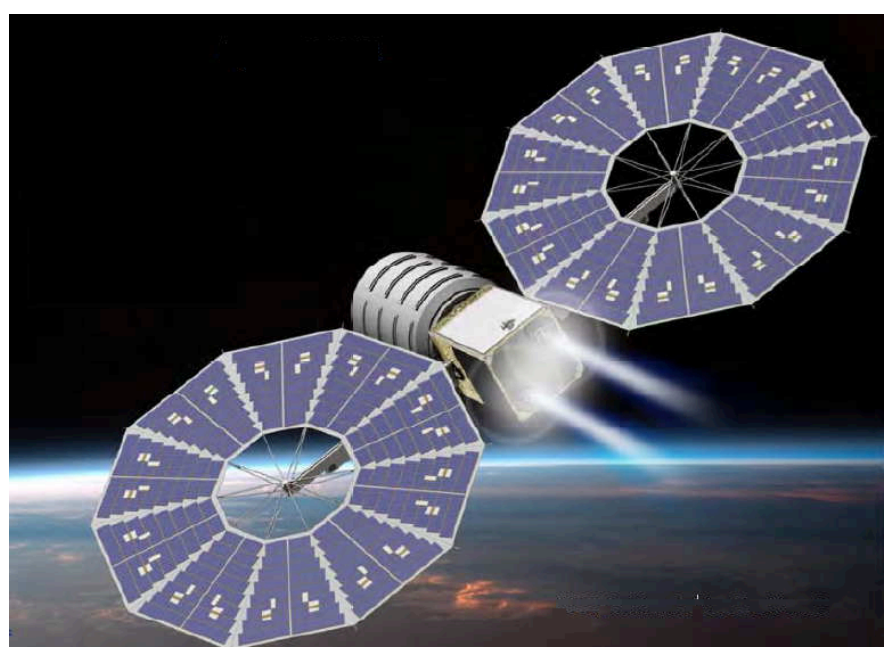

Fig. 3. Design study for a SEP technology demonstration mission.

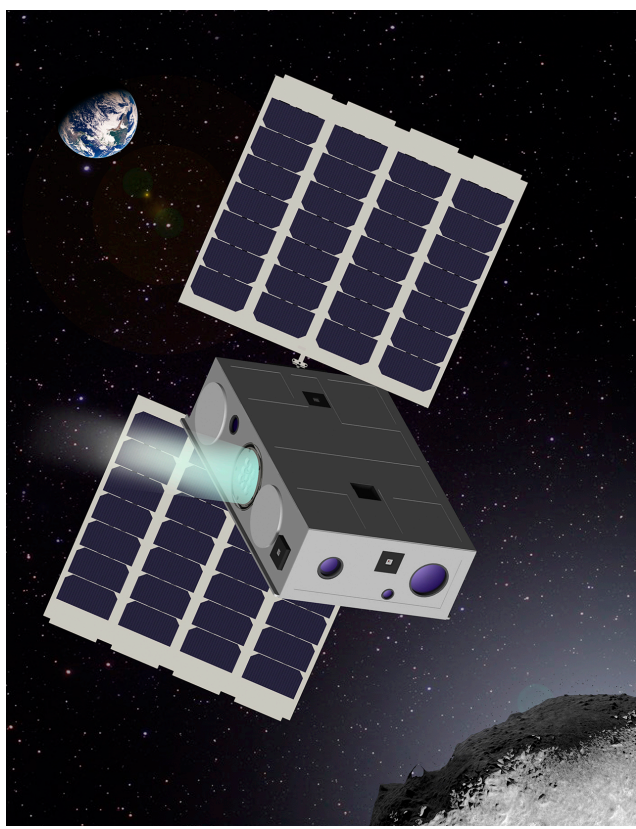

Fig. 4. DAVID spacecraft design study.

\section{RoBOtiC PROBE Missions}

In addition to the asteroid redirect mission and the human Mars mission, solar electric propulsion is a valuable option for robotic probes to explore the solar system. Solar electric propulsion has been analyzed for a number of missions [9, 10], including Mercury missions, asteroid sample return, return of samples from the Martian moons Deimos and Phobos [11], and missions to the outer solar system. 
Figure 4 shows one SEP spacecraft design study, the Diminutive Asteroid Visitor Using Ion Drive (DAVID) spacecraft, a small spacecraft designed to do a solar electric propulsion technology demonstration in an asteroid flyby mission [12].

\section{TECHNOLOGY DEVELOPMENT AND MATURATION}

In support of the Solar Electric Propulsion program, NASA has embarked on a technology development and maturation program to bring the relevant technologies to a technology readiness level (TRL) for flight. Table 1 shows the Space Technology Mission Directorate (STMD) Solar Electric Propulsion technology development goals.

In addition to developing lighter, higher efficiency solar cells for the arrays [13], radiation hardness of advanced IMM cell technology must be improved, in order to allow operation without degradation on orbits spiraling through the Earth's Van Allen belts. A trade-off is to use solar concentration, allowing more shielding on the cells without added weight, but the requirements for stringent sun-pointing may make concentration approaches impractical.

The effect of the engine exhaust plume is also a consideration for solar arrays for SEP missions. Photovoltaic coupon samples were tested under conditions representative of those expected at the 45-degree keep-out zone of the exhaust plume of Hall effect thrusters [14]. The testing (figure 4) showed that mounting designs exist such that there is negligible current collection from the exhaust under a $+600 \mathrm{~V}$ bias, no sustained arcing at a $-600 \mathrm{~V}$ bias, and no damage to the cells. Dark and/or light I-V testing and electroluminescence testing confirmed no damage to the PV cells after acoustic/vibration testing and thermal vacuum wing deployment.

It is also critical to design array structures that deploy the area required for SEP demonstration missions at levels of $\sim 20$ to $40 \mathrm{~kW}$ per wing, yet demonstrating the basic principles and approach that shows the ability to be developed to larger, potentially multi-hundred kilowatt array levels, for future missions. Two arrays under development have reached technology readiness level TRL-5, the MegaFlex and the ROSA designs, with thermal vacuum deployment, vacuum deployed dynamics, and vibration testing complete [14]. Figures 4 and 5 show engineering development units of arrays under development, both $20-\mathrm{kW}$ class arrays with the potential for development to higher power levels.

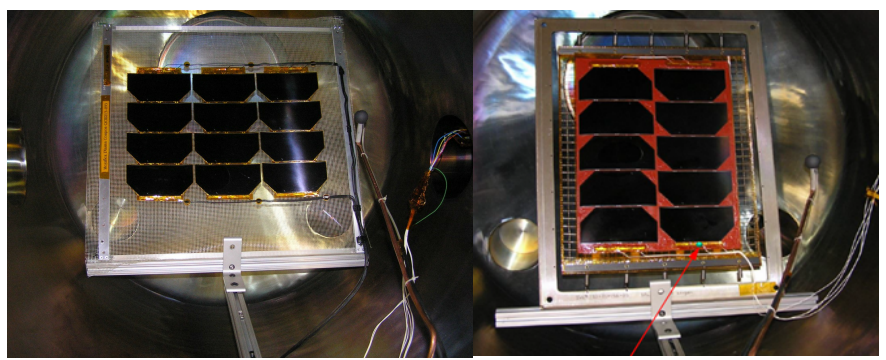

Fig. 4. Coupon tests of solar array sub-units for exposure to Hall-effect thruster plumes.

\begin{tabular}{|c|c|c|c|c|}
\hline Parameter & $\begin{array}{c}\text { SOA } \\
\text { (Typical Large GEO) }\end{array}$ & Goal & Goal / SOA & Comment \\
\hline $\begin{array}{l}\text { Mission } \\
\text { environments }\end{array}$ & $\begin{array}{l}5 \times 10^{14} \mathrm{DENI} \\
0.1 \mathrm{eV}, 1 \mathrm{e} 6 / \mathrm{cm}^{3}\end{array}$ & $\begin{array}{l}2 \times 10^{15} \text { DENI } \\
5 \mathrm{ev}, 1 \mathrm{e} 8 / \mathrm{cm}^{3}\end{array}$ & $\begin{array}{l}4 X \\
10-100 X\end{array}$ & $\begin{array}{l}300 \text { day LEO to GEO protons } \\
\text { HET EP induced plasma }\end{array}$ \\
\hline Power & $<20 \mathrm{~kW}$ & $\begin{array}{l}30 \mathrm{~kW}-50 \mathrm{~kW}, \\
\text { extensible to }>250 \mathrm{~kW}\end{array}$ & $1.5 X-10 X$ & 2 wings, SOA triple-junction cells \\
\hline Voltage & $32 \mathrm{~V}$ to $105 \mathrm{~V}$ & $160 V-300 V$ & $1.5 X-3 X$ & $\begin{array}{l}\text { Must operate in environments from no } \\
\text { plasma to dense EP-induced plasma }\end{array}$ \\
\hline Specific Mass & $60 \mathrm{~W} / \mathrm{kg}$ & $>100 \mathrm{~W} / \mathrm{kg}$ & $1.7 \mathrm{X}$ & \multirow{2}{*}{$\begin{array}{l}\text { End of life power. } \\
\text { Beginning of life power. }\end{array}$} \\
\hline $\begin{array}{l}\text { Stowed } \\
\text { Volume }\end{array}$ & $10 \mathrm{~kW} / \mathrm{m}^{3}$ & $>40 \mathrm{~kW} / \mathrm{m}^{3}$ & $4 X$ & \\
\hline $\begin{array}{l}\text { Deployed } \\
\text { Strength }\end{array}$ & $0.005 \mathrm{~g}$ & $>0.1 \mathrm{~g}$ & $20 \mathrm{X}$ & \multirow{2}{*}{$\begin{array}{l}\text { Dynamic docking, propulsion t/w, } \\
\text { plume impingement loads. }\end{array}$} \\
\hline $\begin{array}{l}\text { Deployed } \\
\text { Frequency }\end{array}$ & $>0.05 \mathrm{~Hz}$ & $>0.1 \mathrm{~Hz}$ & $2 X$ & \\
\hline
\end{tabular}

Table 1: STMD Solar Electric Propulsion technology development goals, comparing desired parameters to the current state of the art. 


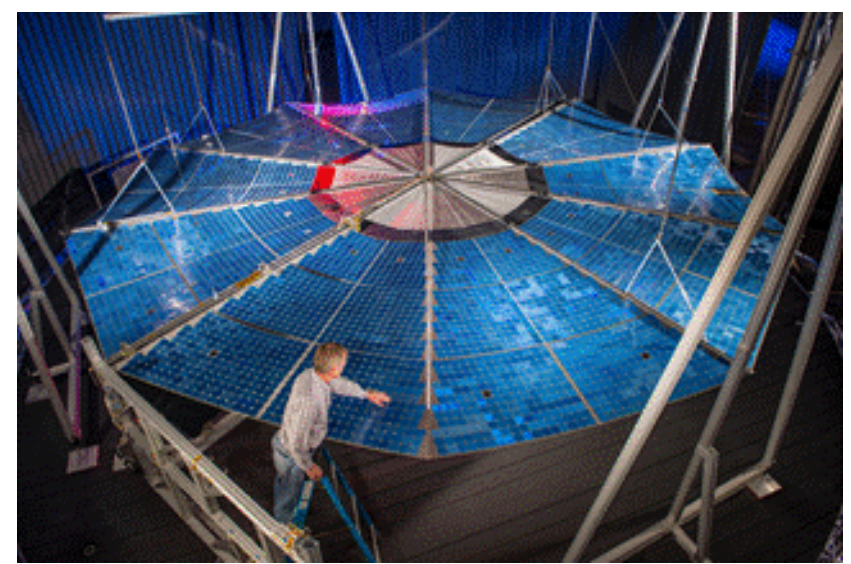

Fig. 5: Deployment tests of development unit of 9.7-meter diameter, $16.8 \mathrm{~kW}$ "MegaFlex" array for the SEP Test mission.

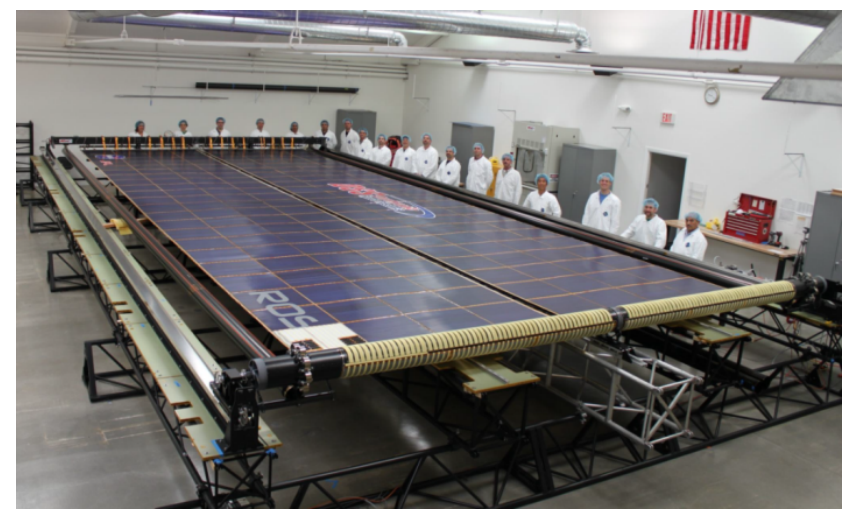

Fig. 6. Deployment test of engineering unit of $6.5 \mathrm{~m}$ by 13.1 m (2:1 aspect ratio) $18.2 \mathrm{~kW}$ "ROSA" array for SEP Test mission.

\section{CONCLUSIONS}

Solar electric propulsion is an exciting option for future exploration missions. In support of the Solar Electric Propulsion program, NASA has embarked on a technology development and maturation program to bring the relevant technologies to a technology readiness level for flight.

\section{REFERENCES}

[1] M. LaPointe, S. Oleson, E. Pencil, C. Mercer and D. Distefano, "MW-Class Electric Propulsion System Designs, AIAA Space 2011 Conference, Long Beach CA, Sept. 2011.

[2] D. Landau, N. Strange, M. Adler, B. Sherwood, J. Polk and J. Brophy, "Human Exploration of Near-Earth Asteroids via Solar Electric Propulsion," American Astronomical Society, 42nd DPS meeting, paper 49.25, Pasadena, CA, Oct. 4-8, 2010.

[3] C. Mercer, S. Oleson, M. Piszczor, K. Bury, E. Pencil, L. Mason, D. Manzella, T. Kerslake, J. Hojnicki, J. Brophy, "Benefits of Power and Propulsion Technology for a Piloted Electric Vehicle to an Asteroid," paper AIAA-2011-7252, AIAA Space 2011 Conference \& Exposition, Long Beach CA, Sept. 27-29, 2011.

[4] NASA, "Bus Concepts to Support the Asteroid Redirect Robotic Mission and In-Space Robotic Servicing Spacecraft," Asteroid Redirect Mission Virtual Industry Day, May 22, 2015
[5] K. Hack, L. Geffert and J. George, "Solar Electric Propulsion," chapter A5.1, Reference Mission Version 3.0 Addendum to the Human Exploration of Mars: The Reference Mission of the NASA Mars Exploration Study Team (B. G. Drake, editor), June 1998.

[6] M. D. Rayman, P. Varghese, D. H. Lehman and L. L. Livesay, "Results from the Deep Space 1 technology validation mission," Acta Astronautica, Volume 47, No. 2-9, July-November 2000, pp. 475-487. doi:10.1016/S0094-5765(00)00087-4.

[7] J. R. Brophy, et al., "The Ion Propulsion System for Dawn," paper AIAA-2003-4542, 39th AIAA/ASME/ SAE/ASEE Joint Propulsion Conference \& Exhibit, Huntsville, AL, July 202003.

[8] Melissa L.McGuire, et al., "Concept designs for NASA's Solar Electric Propulsion Technology Demonstration Mission," paper AIAA2014-3717, 50th AIAA/ASME/SAE/ASEE Joint Propulsion Conference, Cleveland, OH, 2014.

[9] G. Landis, S. Oleson, M. McGuire, J. Fincannon, and K. Bury, "Solar Electric Propulsion for Advanced Planetary Missions," 37th IEEE Photovoltaic Specialists Conference, Seattle WA, June 19-24, 2011.

[10] G. Landis, S. Oleson, M. McGuire, J. Fincannon, and K. Bury, "Design Studies of Planetary Spacecraft Using Solar Electric Propulsion," IAF Global Space Exploration Conference, Washington DC, May 22-24 2012.

[11] S. Oleson, et al., "Phobos and Deimos Sample Return Mission Using Solar Electric Propulsion," paper AIAA 2009-6518, AIAA Space 2009 Conference \& Exposition, Pasadena CA, Sept. 14-17 2009; see also COMPASS Final Report: Mars Moons Sampler, NASA Glenn Report CD-2008-23, April 2008.

[12] G. Landis et al., "A Cubesat Asteroid Mission: Propulsion Tradeoffs," paper AIAA-2014-3755, AIAA Propulsion and Energy Forum, Cleveland OH, July 28-30, 2014.

[13] M. F. Piszczor, et al., "Advanced Solar Cell and Array Technology for NASA Deep Space Missions," Proc. 33rd IEEE Photovoltaic Specialists Conference, pp. 513-517, San Diego CA, May 11-16, 2008.

[14] D. M Goebel, et al., 13th international Spacecraft Charging Technology Conference, Pasadena, CA, June 23-27 2014

[15] Richard Pappa, et al.,, "Solar Array Structures for $300 \mathrm{~kW}-$ Class Spacecraft," Space Power Workshop, Manhatten Beach, CA, April 23, 2013

[16] B. Spence, et al., "UltraFlex-175 Solar Array Technology Maturation Achievements for NASA's New Millennium Program (NMP) Space Technology 8 (ST8)," Proc. 4th World Conf. on Photovoltaic Energy Conversion, Waikoloa, HI, pp. 1946-1950, May 7$12,2006$. 